\title{
REDES DE SOLIDARIEDADE, PANDEMIA E VIOLÊNCIA ESTATAL: UMAAPROXIMAÇÃO A PARTIR DE AÇÕES COLETIVAS DE COMUNICAÇÃO EM FAVELAS CARIOCAS
}

SOLIDARITY NETWORKS, PANDEMIC AND STATE VIOLENCE: AN APPROACH BASED ON COLLECTIVE COMMUNICATION ACTIONS IN RIO DE JANEIRO SLUMS

Patrícia Lânes

Doutora em Antropologia pelo Programa de Pós-graduação em Antropologia da Universidade Federal Fluminense (PPGA/UFF), pesquisadora de pós-doutorado no Programa de Pós-graduação em Ciências Sociais da Universidade do Estado do Rio de Janeiro (UERJ), onde é bolsista PNPD/Capes. Integrante dos grupos de pesquisa CIDADES - Núcleo de Pesquisa Urbana e DALE! - Decolonizar a América Latina e seus Espaços. Atua sobretudo nas temáticas de juventude, favela, movimentos sociais urbanos e memória coletiva através de abordagens que privilegiam os debates sobre trajetória, cidade, engajamento militante e relações raciais. 


\section{RESUMO}

O presente artigo tem como objeto a análise de uma parte das mobilizações mais recentes protagonizados por ações coletivas locais, a partir da experiência do Complexo do Alemão, zona norte da cidade do Rio de Janeiro (RJ), que agiram conjuntamente na mobilização de recursos e disseminação de informações nos primeiros meses da pandemia global do coronavírus, em 2020. O conjunto de estratégias das quais lançaram mão englobam campanhas e o uso de meios de comunicação variados, notadamente a internet e suas plataformas, a fim de dar visibilidade para a situação de favelas e periferias naquele momento, incorporando um amplo repertório utilizado em seu cotidiano para lidar com precariedades variadas impostas pela ação estatal em vários níveis. A comunicação comunitária é aqui tomada para pensar de que maneiras ações coletivas se mobilizam e interferem positivamente em contextos de violação de direitos criados pela pandemia do coronavírus e agravados pela violência estatal.

Palavras-chave: comunicação comunitária; ação coletiva; favela; pandemia.

\section{ABSTRACT}

The purpose of this article is to analyze a part of the most recent collective mobilizations led by local collective actions, based on the experience of Complexo do Alemão, in the northern part of the city of Rio de Janeiro, which acted together in the mobilization of resources and dissemination of information in the first months of the global coronavirus pandemic in 2020. The set of strategies they used included campaigns and the use of various means of communication, notably the Internet and its platforms, in order to give visibility to the situation of favelas (slums) and peripheries at that time, incorporating a wide repertoire used in their daily lives to deal with various precarious conditions imposed by state action at various levels. Community communication is taken here to think about the ways in which collective actions are mobilized and positively interfere in contexts of violation of rights created by the coronavirus pandemic and aggravated by state violence.

Keywords: community communication; collective action; favela; pandemic. 
"Minha aposta hoje em dia está nas e pelas esperanças pequenas. Ou seja, em e por esses 'modos muito outros' de pensar, saber, estar, ser, sentir, fazer e viver que sim são possíveis e, além disso, existem apesar do sistema, desafiando, transgredindo, fazendoo fissurar. [...] Minha aposta, então, é desaprender a pensar a partir do universo da totalidade e aprender a pensar e atuar em seus arredores, fissuras e brechas, onde moram, brotam e crescem os 'modos outros', as esperanças pequenas." ${ }^{1}$

Catherine Walsh

\section{Introdução}

No final de 20I3, fortes chuvas impactaram negativamente a população da cidade do Rio de Janeiro. Naquele ano, uma vez mais, áreas vulneráveis foram as mais atingidas. Acompanhei momentos da mobilização de diferentes ações coletivas locais (TILLY, 1978) do Complexo do Alemão que se articulavam para lidar com pessoas desabrigadas ou que viviam em áreas de risco e precisavam de assistências variadas por parte de agentes estatais.

Sete anos depois, em 2020, diversas pessoas, organizações e coletivos com atividades e modos de atuação específicos articulavam-se novamente para tentar preparar as favelas que fazem parte do complexo para a realidade de uma pandemia que se anunciava no Brasil após notícias de contaminação em outras partes do mundo. As ações envolveram a criação de um "gabinete de crise"; campanhas solicitando doações através de redes sociais virtuais e meios de comunicação de massa; distribuição de cestas básicas e kits de higiene; denúncia da falta de água em várias localidades; e investimento na comunicação comunitária. Este último, foco do presente texto.

Voltando um pouco mais no tempo, antes de chegar de vez em 2020, retorno até 20I2, quando entrei pela primeira vez no Alemão a fim de entrevistar algumas pessoas que lá viviam para uma pesquisa sobre o uso das Novas Tecnologias de Comunicação e Informação (NTICs, como usava o senso comum) para reivindicação de direitos entre jovens de espaços populares. Foi então que conheci importantes interlocutores(as) e que reencontrei David Amen, com quem havia trabalhado anos antes em uma organização não governamental (ONG).

\footnotetext{
${ }^{1}$ No original, em espanhol: "Mi apuesta hoy en día está en y por las esperanzas pequeñas. Es decir, en y por esos 'modos muy otros' de pensar, saber, estar, ser, sentir, hacer y vivir que sí son posibles y, además, exis-ten a pesar del sistema, desafiándole, transgrediéndole, haciéndole fisurar. [...] Mi apuesta entonces es desaprender a pensar desde el universo de la totalidad y aprender a pensar y a actuar en sus afueras, fisuras y grietas, donde moran, brotan y crecen los 'modos otros', las esperanzas pequeñas."
} 
Jornalista e grafiteiro, um dos criadores do Instituto Raízes em Movimento, David compartilhou, em entrevista, algumas de suas reflexões sobre o que compreendia como tecnologia:

Cada tecnologia, na verdade, tem potencial também... Quando digo a tecnologia estou indo muito além do que a gente entende sobre tecnologia, sabe? A palavra é uma tecnologia. A caneta é uma tecnologia. O celular, a câmera digital, a filmadora, o computador, uma ilha de edição, né? O homem é uma tecnologia, né?! A gente acredita que a partir desse pensamento, desse entendimento é possível se construir, se fazer. Independente se vai ficar uma coisa padronizada. $\mathrm{E}$ eu acho que é um pouco quebrar esse padrão de qualidade que as grandes emissoras, principalmente de televisão, (criam) $[\ldots . .]^{2}$

O que ouvi naquele momento, mas tive dificuldade de entender, foi que não só de internet e celular se vive. E se as novas tecnologias mudam nossas percepções sobre tempo e espaço, nossos modos de comunicar e de olhar, nossas formas de fazer pesquisa, as "velhas" não saem de todo de cena. Esse foi um dos aspectos que pude perceber ao longo de meu trabalho de campo no doutorado e no pós-doutorado, acompanhando ações coletivas no Complexo Alemão lá (naquele lugar geográfico) e aqui (de casa, da rua, do transporte público etc., mediada pelo celular ou pelo computador), buscando, como sugerem Miller e Slater (2000), uma etnografia que não estabeleça uma cisão intransponível entre "real" e "virtual", como também me ensinaram pessoas e grupos que conheci e com os quais trabalhei na pesquisa. Era preciso, então, entender que as relações sociais e, portanto, os engajamentos militantes, os ativismos, as mobilizações e as ações sociais se fazem em continuidades, descontinuidades, tensões e reproduções entre aquilo que é feito nas plataformas da internet e fora delas.

As tecnologias de comunicação podem ser compreendidas como parte do repertório de coletivos, organizações e indivíduos pesquisados uma vez que o uso contínuo das redes sociais e plataformas virtuais com finalidades de engajamento foi encontrado rotineiramente ao longo da pesquisa. Como observa Tilly (1978), o repertório da ação coletiva em dado momento histórico e contexto social é limitado. Ainda de acordo com o autor, o uso de um mesmo repertório aponta para uma gramática cultural e histórica disponível que é interpretada pela sociedade e pelos seus grupos sociais". E ele é produzido e reproduzido por

\footnotetext{
${ }^{2}$ Informação verbal (2012).
} 
diferentes atores coletivos na medida em que é vivido, testemunhado ou conhecido (através dos meios de comunicação ou de livros, por exemplo).

$\mathrm{Na}$ história recente do Alemão, o testemunho de experiências positivas de visibilidade que tiveram impacto na constituição de atores e agendas locais certamente contribuiu para a ênfase dada por muitos coletivos, grupos e pessoas à realização de campanhas (através da utilização de hashtags, por exemplo) e à circulação de textos e imagens em redes sociais como estratégias privilegiadas de atuação pública. Essa incorporação, ao mesmo tempo que reproduz, contribui para alargar o repertório da ação coletiva local. É realizada em combinação com outras estratégias, como a ocupação física e pontual de espaços públicos com atividades culturais, reuniões com atores internos e externos, produção de documentos, organização de caminhadas e manifestações públicas, para ficar em alguns exemplos. Todas essas estratégias, no entanto, combinavam-se em certa medida com o uso das redes sociais.

A reflexão que apresento a seguir tem como objeto analisar uma parte das mobilizações mais recentes protagonizadas por ações coletivas locais, a partir da experiência do Complexo do Alemão, zona norte da cidade do Rio de Janeiro, mas não limitadas a elas. É importante entender que, historicamente, as ações coletivas de favelas e periferias constroem redes de solidariedade e articulação internas (ou seja, reúnem diferentes grupos locais em prol de um objetivo comum), mas também entre favelas, periferias e atores sociais localizados em diferentes espaços das cidades e do país, e mesmo fora dele.

Nesse sentido, a internet, suas redes sociais e plataformas tem se mostrado meio importante de troca de informações entre militantes e entre estes e moradores(as) não engajados (SOUZA, 2OI7; MANO, 20I8), bem como de mobilização de recursos para que tais iniciativas se tornem mais visíveis socialmente e, em casos como os da pandemia e da violência estatal aqui tratados, possam sensibilizar e engajar outros setores da sociedade a partir de suas pautas e narrativas. Nesse processo, textos e imagens operam significativos recursos graças, por um lado, à popularização da internet e de dispositivos móveis (como celulares a ela conectados), mas também à possibilidade de registro visual das questões levantadas por ativistas tendo a imagem como aliada.

É importante ter em mente que, em muitos casos, tais ativistas são também pessoas que investiram na profissionalização e especialização da comunicação, tornando-se fotógrafos e jornalistas certificados e graduados. Configuram-se, desse modo, novas conformações da comunicação comunitária. Retomando as reflexões trazidas por Amen, desta vez durante 
evento realizado no Complexo do Alemão, em 2019, ${ }^{3}$ se usualmente a comunicação é pensada como "dar notícia pra fora ou pra dentro, então a gente não faz comunicação comunitária, a comunicação se dá pela interação com o morador, não só como objeto ou personagem (de uma notícia), mas como produtor, como quem está fazendo. A gente faz comunicação que interage, que troca, que sente". São essas compreensões acerca das ideias de tecnologia e comunicação cunhadas por David que tomo como ponto de partida para analisar a conformação do que pode ser compreendido como comunicação comunitária ou popular no contexto da pandemia, agravado pela continuidade das operações policiais dentro de favelas realizadas no primeiro momento da proliferação do coronavírus (sobretudo entre os meses de março e maio de 2020). Trata-se, portanto, de um recorte possível de um cenário mais amplo de movimentos populares urbanos no início da pandemia no Rio de Janeiro.

\section{Comunicação comunitária, redes de solidariedade e pandemia}

A comunicação comunitária ou popular pode ser compreendida como modos de comunicar de movimentos sociais populares em toda a sua imensa variedade, tanto em termos temporais e espaciais, quanto no que se refere a modos de atuação e meios mobilizados para tanto (aqui exploraremos mais detidamente os usos da internet e diferentes plataformas digitais). Isso quer dizer que não existe um modo único, ou apenas UMA coisa que possa ser chamada de comunicação comunitária ou popular. Rádios comunitárias, panfletos, jornais impressos, rádio-poste, atividades públicas, grafites, cartazes e faixas e, mais recentemente, certa modalidade de "ativismo virtual" podem fazer parte dela.

Há uma ampla bibliografia sobre o tema e aqui cito apenas algumas poucas referências incontornáveis. Custodio (2016), em sua tese de doutorado sobre o tema (a que se refere como mídia-ativismo em favelas), chama atenção para essa multiplicidade e também para o que há em comum entre essas muitas formas de ação de comunicação em favela. O reconhecimento mútuo desses atores entre si costuma passar por duas dimensões. A primeira, diz respeito à reconstrução crítica de estereótipos que circulam na mídia comercial sobre favelas, periferias e seus moradores, fazendo um contraponto a narrativas hegemônicas que reificam tais espaços e pessoas como "carentes", "violentos" e "criminosos". Para tanto, mobilizam um amplo repertório de narrativas, a partir do lugar, sobre "o que há de positivo nas favelas": a cultura, o lazer, a paisagem, a história do lugar e seus personagens, as dinâmicas de

\footnotetext{
${ }^{3}$ Trata-se da última edição do evento Circulando - Diálogo e Comunicação na Favela, organizado anualmente pelo Instituto Raízes em Movimento, que mobiliza diferentes pessoas e grupos a partir de sua rede de relações, para um ou mais dias de encontro com debates e atividades culturais no Complexo de Alemão. Informação verbal (2019).
} 
resistência e as redes de solidariedade, entre outros aspectos e temáticas. A partir daí, e para isso as imagens e o audiovisual são considerados fundamentais, buscam construir narrativas que se opõem a esses estereótipos, revelando a "potência" do lugar.

A segunda dimensão comum a esses diferentes atores é o registro e a denúncia de "violações de direitos" cometidas por agentes do Estado e outros atores, sobretudo externos, contra seus moradores. As práticas de violação da polícia nesses locais ganham especial relevância por atentar diretamente contra a vida das pessoas, resultando em inúmeras mortes, mas também em restrições no ir e vir de moradores(as) (que afetam o acesso a trabalho, educação, lazer, saúde e outros direitos já estabelecidos historicamente nesses locais de maneira precária pelo Estado a partir de lutas sociais). Muitos dos meios de comunicação comunitária e as pessoas a eles vinculadas colocam-se como protagonistas de denúncias contra tais violações, o que não raro resulta em perseguição e ameaças (MARTINS, 20I8).

No entanto, essas não são as únicas denúncias realizadas por essas mídias, aparecem também matérias sobre violação no direito à moradia (do qual a remoção é seu lado mais visível), ao saneamento básico, à saúde, ao lazer etc. Ou seja, a precariedade que é recorrente e historicamente marca a ação do Estado junto a essas populações, que acaba por produzir tais territórios e boa parte das representações hegemônicas sobre eles, é alvo constante de publicização dessa mídia, que compõe o repertório mais amplo das lutas e mobilizações políticas e sociais no local e na cidade como um todo.

Há ainda que enfatizar o lado coletivo e interno dessas práticas comunicativas. Ainda que, na última década, devido à popularização da internet e de dispositivos através dos quais o acesso passa a ser móvel, essas notícias, narrativas e denúncias estejam circulando para além dos locais e de seus apoiadores tradicionais (movimentos sociais, organizações de direitos humanos, representantes do poder público etc.) através de e-mails, blogs e redes sociais, há cobrança entre os próprios atores que estão à frente dessas ações para que o trabalho principal (como já apontou Amen na citação inicial) deva ser para dentro, para os moradores(as), e nem sempre externamente publicizado. "Quem vê close, não vê corre", como diz um ditado contemporâneo que se refere ao fato do que é exibido e visto através das redes sociais não revelar a quantidade de trabalho e investimento envolvidos na produção do que é tornado público por tais meios. Dessa maneira, boa parte dessas ações pode permanecer invisível para a população que não vive nesses locais, mas continua sendo considerada a razão de ser de tais coletivos, grupos, pessoas e organizações.

As campanhas começaram ainda nas primeiras semanas de quarentena, quando as informações a respeito da Covid-I9 eram escassas e as estratégias de combate à disseminação 
do vírus, confusas e, por vezes, contraditórias. Membros desses coletivos locais de comunicação que já trabalhavam em favelas e periferias buscavam entender o que estava acontecendo e como aquilo podia ser traduzido para as realidades nas quais atuavam. A primeira restrição de não sair de casa fazia pouco sentido em muitos lugares, já que para grande parte das pessoas que moram nesses locais era impensável exercer o agora, popularizado home office. Parar de sair para trabalhar significava deixar de receber salário, fosse porque poderia ser reduzido ou cortado por patrões e patroas, fosse porque "quem não vende, não recebe", no caso de tantos trabalhadores precarizados também residentes nessas localidades. Sem nenhuma perspectiva de auxílio emergencial naquele momento, o que fazer?

Além disso, "ficar em casa" poderia significar passar o dia em ambientes pequenos e pouco ventilados, onde aquilo que pode parecer simples, como lavar as mãos com sabão constantemente, não era possível devido, por exemplo, ao acesso descontínuo à água. $\mathrm{O}$ uso de álcool para higienização também não era possível em muitos casos devido ao alto custo e à dificuldade de acesso (sobretudo nos primeiros meses de pandemia, quando a grande procura resultou na alta dos preços e na escassez do produto no mercado).

Havia também, naquele momento, algo que permanece um ano depois do início da pandemia no país: a disseminação das chamadas fake news, quando boatos e notícias falsas se propagavam pelas redes sociais, tendo eco em governantes (especialmente o então presidente do país, Jair Bolsonaro) que constantemente minimizavam a gravidade do que estava acontecendo, indo na contramão de órgãos internacionais de saúde e da realidade de outros países, ${ }^{4}$ como a China, que já viviam os efeitos devastadores da pandemia, com a morte de centenas e, depois, de milhares de pessoas e o colapso de sistemas de saúde. Foi nesse cenário que ações coletivas locais se viram interpeladas a fazer alguma coisa. Não foram apenas aquelas relacionadas à comunicação que se mobilizaram, mas elas tiveram papel decisivo na organização e na disseminação das informações e no esclarecimento de dúvidas da população.

O caso do Complexo do Alemão é, nesse sentido, bom para pensar não só a realidade daquele local, mas também o que estava acontecendo mais amplamente em diversas periferias. Lá, o histórico de organização comunitária é longo. Foi o caso de grande parte das favelas cariocas, anterior a investimentos públicos feitos na região. A primeira associação de moradores em uma das favelas do Complexo data da década de I960, e são inúmeras as histórias narradas sobre mutirões e organização de comitês comunitários.

\footnotetext{
${ }^{4}$ Ver em:<https://www.cartacapital.com.br/saude/mpf-processa-governo-por-campanha-de-bolsonaro-pelo-fim-do-isolamento/>.

${ }^{5}$ Para mais informações sobre a história do Complexo do Alemão com ênfase na atuação de diferentes modalidades de ações coletivas locais, ver Instituto Raízes em Movimento (2013); Velloso et al. (2013); Rodrigues (2016) e Cunha (2016).
} 
O caso do Complexo do Alemão revela a possibilidade de reativação de estratégias de mobilização e de redes de solidariedade e comunicação que não foram criadas em $2020 \mathrm{em}$ razão da pandemia. Foram muitas as experiências anteriores de articulação entre ações coletivas locais em torno de um objetivo comum. Comitês, campanhas, reuniões e mobilizações públicas foram construídas antes a partir dessa lógica. Em dezembro de 20I3, como já mencionado, quando fortes chuvas caíram sobre o Rio de Janeiro e seu impacto sobre a população e os diferentes territórios fez com que moradores de "áreas de risco" nas favelas tivessem seus locais de moradia comprometidos, gerou a articulação de organizações locais para auxiliar na denúncia sobre a lentidão de resposta pelo poder público e o deslocamento de parte dessas pessoas que não puderam continuar em suas casas aguardando resposta de órgãos do Estado.

Final de novembro, início de dezembro de 2013, choveu, choveu, choveu, e aí começou a acontecer aquelas coisas. Na verdade, foi a primeira chamada da rede (se refere às redes sociais) da chuva foi minha. [...] Porque meu irmão, a casa dele caiu uma pedra dentro e minha cunhada não conseguia acessar a Defesa Civil de jeito nenhum. Ligava... [...]. E aí eu fiz uma chamada na rede: "Gente, por favor!". Aí a Marize (Marize Cunha, pesquisadora, amiga de Renata) que compartilhou no Twitter, e aí começou todo mundo a se ligar de que a tragédia no Alemão seria maior se ninguém convocasse. Aí a gente começou a fazer, aí juntou, entendeu? Foi a primeira vez que eu vi as instituições no Alemão tão juntas, sem brigar e sem ego, né? (Entrevista com Renata Trajano, integrante do coletivo Papo Reto, em 2015, grifo nosso)

Relatos como esse, feitos por moradores engajados através das redes sociais, articulavam-se a um trabalho de gestão cotidiana de dois abrigos organizados e geridos por organizações locais. Em ambos, doações de roupas e alimentos, além de contribuições financeiras eram aceitas e buscavam-se formas de mobilizar agentes estatais para lidar com a situação. As estratégias dos abrigos eram distintas e revelavam alianças e conflitos não apenas entre diferentes atores internos, mas também entre eles e políticos e atores externos.

Entre alianças e conflitos, expressavam-se também modos de ver o mundo e conceber a ação coletiva e o papel de pessoas engajadas, e de organizações e coletivos dos quais participavam (SOUZA, 20I7). A comunicação interna e externa foi uma das principais estratégias naquele episódio. Era necessário mobilizar recursos, não apenas entre a população local, como doações em dinheiro, roupas e alimentos para as pessoas desabrigadas. As doações tinham que ser separadas e organizadas (no caso de roupas), transformadas em refeição e distribuídas pelos residentes dos abrigos e revertidas em outros 
bens de consumo necessários naquele momento (como materiais de limpeza e higiene). Aquela experiência foi fundamental não apenas para lidar com uma situação emergencial, mas como experiência pedagógica e política para as pessoas diretamente envolvidas na organização dos abrigos. Prova disso foi a formação de um novo coletivo local, o Papo Reto, integrado por pessoas que já se conheciam, mas que se aproximaram naquelas semanas. Laços de confiança e identificação política foram ali criados ou reforçados.

Ressalta-se, também, que assim como no Complexo do Alemão, o Complexo da Maré e outras favelas, periferias e bairros populares (para ficar no caso dos meios urbanos) já exerciam estratégias de mobilização em seus cotidianos que podem se tornar mais visíveis para os "de fora" em momentos de crises que ultrapassam as fronteiras concretas e simbólicas que separam favelas e o restante da cidade. Foi o caso das chuvas de 2013 e tem sido também o do assassinato de crianças e jovens pela polícia (que será retomado adiante), bem como o da pandemia de coronavírus em 2020 e 202 I. A cada nova "crise" protagonizada pelo Estado em suas múltiplas agências (e pela maneira com a qual agentes estatais lidam com elas), rearticulam-se pessoas e organizações locais que, em seus cotidianos, não obrigatoriamente trabalham em aliança, mas entre as quais circula uma enorme quantidade de informações.

Em meados de março de 2020 , coletivos e organizações locais, ao saberem das implicações iniciais da pandemia, então em seu início no Brasil e no Rio de Janeiro, começaram a se mobilizar em conjunto. A convocação foi feita por Camila Santos, moradora da Fazendinha, liderança da luta por moradia e do Mulheres do Alemão em Ação. Outras pessoas e ações coletivas entre as mobilizadas fizeram chamados para suas redes de fora e de dentro do complexo: doações eram necessárias e urgentes (THAMARA, 2020).

Esse chamado foi um dos responsáveis pela reorganização do Juntos pelo Complexo do Alemão, articulação criada pelo Raízes em Movimento (do qual o já citado David Amen é uma das principais referências) e, logo depois, pela organização do Gabinete de Crise do Complexo do Alemão. Enquanto o gabinete foi formado pelos grupos Mulheres em Ação no Alemão, Coletivo Papo Reto e Voz das Comunidades; o Juntos pelo Complexo do Alemão reunia o Instituto Raízes em Movimento, a Escola Quilombista Dandara de Palmares (desdobramento do Coletivo Ocupa Alemão) e o Espaço Democrático de União, Convivência, Aprendizagem e Prevenção (Educap). Apesar da opção pela organização em articulações distintas, ambas dialogavam entre si e trocavam informações e também doações para que tudo o que chegasse pudesse ser entregue aos(às) moradores(as) que precisavam.

Com os primeiros recursos recebidos, produziram-se faixas que foram colocadas em lugares de grande movimento. Imagens dessas faixas que circularam na internet (algumas 
com pessoas das ações coletivas segurando-as, outras apenas das faixas já afixadas em diferentes locais) traziam frases como: "Atenção! Descobriram a planta que vai acabar com o coronavírus: "planta" a bunda no sofá e fica em casa! \#CovidigNasFavelas"; "Escolha o bom senso e, se possível, colabore com aquelas e aqueles com menos informações para passarmos bem por esse momento de crise. \#CovidınNasFavelas"; "Sabemos que temos um precário abastecimento de água. Caso você tenha água em casa, compartilhe com quem precisa. \#CovidıgNasFavelas"; ou ainda, "Atenção! Sua saúde é muito importante! Não deixe de lavar as mãos e manter sua casa arejada. \#CovidigNasFavelas". Como é possível notar, os textos que compõem as faixas alertavam para a situação e o que poderia ser feito para minimizar seus efeitos nocivos (às vezes de maneira bem-humorada), chamavam atenção para a solidariedade e, através da utilização da hastag "Covid I9 nas Favelas", incorporavam as familiares faixas à gramática das campanhas na internet que estavam acontecendo não apenas no Alemão. Muitas dessas frases podiam ser encontradas também em pequenos cartazes colados em postes, panfletos e carros de som contratados para percorrer as i 2 favelas do complexo, onde vivem cerca de I2O mil pessoas.

Os pedidos de doações intensificaram-se e também o retorno em relação a elas, o que demandou uma organização ainda maior por parte do gabinete, do Juntos pelo Complexo do Alemão e de outras organizações locais para cadastrar famílias e doações; e separar, higienizar, organizar e distribuir produtos em cestas e kits. Membros de ambas articulações percorreram diferentes localidades do complexo, visitando as casas para entender as demandas de moradores(as) que tinham experiências e demandas variadas. Como me relatou um dos integrantes do Juntos pelo Complexo do Alemão, havia pessoas que poderiam estar em cadastros de programas do Estado (como o Bolsa Família) e não estavam recebendo o benefício, outras que não podiam permanecer em suas casas porque a área externa possibilitava a distração de crianças e idosos e para que não ficassem o tempo inteiro em ambiente fechado e sem circulação de ar.

Além disso, houve a demanda de produzir pequenos vídeos esclarecendo dúvidas recorrentes de moradoras e moradores. O Gabinete de Crise, por exemplo, recolheu através de vídeo dúvidas de mototaxistas sobre a pandemia que foram respondidas por especialistas da área de saúde. Outra modalidade de vídeo utilizada pelo grupo foi a live (veiculação ao vivo de conversas a partir de diferentes redes sociais como Facebook e Instagram). Nas lives, buscavam explicar o papel do gabinete naquele momento, diferenciando seu trabalho de recolhimento e distribuição de doações daquele que deveria estar sendo feito por órgãos estatais como a Secretaria de Assistência Social, por exemplo. Uma terceira modalidade de 
vídeos mais curtos trazia imagens das ações realizadas ao longo de uma semana, incluindo o número de doações recebidas e distribuídas numa espécie de prestação de contas para beneficiados (ou que gostariam de receber as doações) e doadores.

O Voz das Comunidades criou, ainda, um aplicativo para celulares onde mantinham informações atualizadas sobre o número de contaminados na região. Em momento de escassez, ou mesmo de desconhecimento de dados oficiais por parte de governos municipais, estadual e federal, a organização fazia um levantamento, através da visita de seus comunicadores a unidades de saúde da área, buscando contabilizar o impacto do coronavírus no Complexo do Alemão e adjacências. Posteriormente, esses dados passaram a ser veiculados junto com aqueles disponibilizados pela Secretaria Municipal de Saúde. Pelo aplicativo, também veiculavam matérias realizadas pelo grupo contando o dia a dia dos moradores(as) diante da realidade da pandemia, incluindo aquelas sobre as vítimas do vírus.

Simultaneamente, fotos, vídeos e textos eram produzidos e compartilhados nas redes sociais, às quais pessoas de diferentes lugares da cidade, do país e do mundo tinham acesso a essas imagens e informações, tomando também conhecimento das muitas realidades de uma mesma localidade e sendo solicitadas a contribuírem a partir de diferentes modalidades de doação. Para tanto, alguns dos grupos e coletivos em questão utilizavam também redes de relações estabelecidas pela sua presença e visibilidade na internet. Esse foi o caso, por exemplo, do Voz das Comunidades, incialmente um jornal comunitário, criado pelo ainda menino Rene Silva e por amigos da sua escola que, em 2020, tinha mais de 60 mil seguidores no Instagram, entre eles pessoas famosas que já haviam colaborado com ações do grupo em outros momentos, e que estavam sendo reconvocadas a contribuir. Outro caso foi o do mídiaativista Raull Santiago, um dos integrantes do Coletivo Papo Reto, que tinha, sozinho, mais de 50 mil seguidores. Assim como Rene, Raull também tem uma enorme rede de conhecidos dentro e fora do Complexo do Alemão que possibilitava a ampliação do pedido de colaboração no momento de pandemia. As conexões e redes mobilizadas por eles, outras pessoas e grupos permitem que essas informações cheguem a lugares para além dos movimentos sociais populares e mídias comunitárias. Eles e outros comunicadores locais já haviam se tornado referência para grandes veículos de mídia comercial, o que facilitava que o que estava sendo vivenciado de forma específica, e dramática, por muitas pessoas de classes populares fosse disseminado também através desses meios.

Pode-se pensar, assim, na formação de redes de solidariedade que envolvem prioritariamente moradores(as) dessas localidades (incluindo lideranças e integrantes desses coletivos e colaboradores usuais), mas também outras pessoas não moradoras que, sensibilizadas 
pela situação, estavam dispostas a colaborar. Para tanto, foram disponibilizados pontos de entrega de doações e contas correntes de pessoas e instituições tornadas publicamente disponíveis para o depósito de doações em dinheiro. Tais redes de solidariedade em sua extensão e amplitude podem ser pensadas como esporádicas e circunscritas, constituindo-se efeitos determinados no tempo a partir de um "evento crítico" (DAS, 1999) que provoca reações em diferentes grupos sociais, que são reconhecidas e potencializadas por mediadores(as) que transitam por fronteiras geográficas e de comunicação jamais estáticas. Tais formas de organização permitiram não apenas a mobilização de pessoas para doarem e de outras pessoas para somarem no trabalho de distribuição das doações, mas também o compartilhamento entre movimentos sociais de diferentes favelas. Essa outra dimensão das redes de solidariedade em questão é fundamental.

Existe uma histórica relação entre pessoas de diferentes ações coletivas populares, movimentos sociais e organizações de direitos humanos. Essas redes são potencializadas em situações como esta. E as redes sociais virtuais, não apenas as publicizadas para um maior número de pessoas, mas aquelas onde opera maior restrição e controle entre participantes (caso do WhatsApp), tornam-se meio privilegiado que permite a instantânea troca de informações entre os que têm fácil acesso à Internet.

Assim, uma parte das doações que chegavam ao Complexo do Alemão, por exemplo, podia ser distribuída em Acari, revelando um reconhecimento de necessidades e urgências que ultrapassa a ideia de "local" ou de uma "comunidade" fechada em si mesma. As pessoas circulam pela cidade e pelas favelas da cidade, fazendo as doações circularem também. Informações circulam na internet. Redes de solidariedade são ampliadas. Formas de lidar com esse evento crítico são aprendidas, replicadas, adaptadas. As tecnologias criadas por movimentos sociais de uma favela (no sentido proposto inicialmente por Amen) também circulam e são experimentadas em outras. Esse foi o caso do painel com o número de pessoas contaminadas e mortas devido à Covid-I9 pintado por grafiteiros do Complexo da Maré que logo ganhou uma versão no Complexo do Alemão. Ou as contas para depósito de doações em dinheiro que passaram a ser reunidas na mesma postagem e divulgadas coletivamente. Ou, ainda, o uso das hashtags, que agregam ideias e demandas, revelando as informações que são organizadas por comunicadores(as) populares de diversas favelas e periferias, como por exemplo, \#CovidignasPeriferias e \#CovidignasFavelas, por exemplo.

Todas essas mobilizações e ações tiveram que lidar com outra face da realidade de espaços populares e periferias urbanas: a violência estatal. Ao contrário do que se poderia imaginar, uma vez que havia uma ordem pública para que as pessoas permanecessem em 
suas casas devido às crises de saúde e sanitária, as incursões policiais em favelas do Rio de Janeiro não diminuíram, continuando a vitimar diversos moradores, o que significou mais um desafio para quem nunca foi possível permanecer em suas casas: os(as) participantes de organizações e ações coletivas locais.

\section{Violência na pandemia: racismo e mobilização social}

O mês de maio de 2020 foi especialmente cruel para moradores de favelas e periferias do Rio de Janeiro e região metropolitana, como narra a socióloga Marcia Leite, em artigo sobre biopolítica e precariedade durante a pandemia, em I5 de maio de 2020 :

Na manhã de maio de 2020 , as forças de segurança do estado do Rio de Janeiro (Polícia Civil e Polícia Militar, com apoio do Batalhão de Operações Especiais da PMERJ, Bope) realizaram uma operação militar no Complexo do Alemão, conjunto de favelas na Zona Norte da cidade do Rio de Janeiro. Segundo muitos relatos de moradores, eles invadiram a favela, lançaram granadas, atiraram a esmo, atingiram casas, transformadores (cortando a energia elétrica da localidade), "esculacharam" moradores e mataram I3 pessoas. O objetivo declarado da operação foi buscar "o paiol do tráfico", onde estariam armas, munições e drogas. Saíram do Alemão carregando um PM ferido levemente por estilhaços e o "butim" da operação: oito fuzis e alguma droga (há notícias também, ainda controversas, de que teriam sido apreendidas oito granadas). Alguns feridos - levados para a Unidade de Pronto Atendimento (UPA) próxima - logo vieram a falecer. Os policiais deixaram ainda, na parte alta do Complexo do Alemão, ao menos cinco corpos, que tiveram que ser descidos para a rua por moradores. Nela, estes corpos foram pranteados por seus parentes, aglomerados (em momento de pandemia). E deixaram também os moradores em torno de $36 \mathrm{~h}$ sem energia (e, portanto, sem água que pudesse ser carreada por meio de bombas). E consideraram a operação exitosa. (LEITE, 2020, p.5)

As recorrentes, e severamente criticadas por movimentos sociais, coletivos e organizações locais e grupos variados de direitos humanos, operações da Polícia Militar do Rio de Janeiro passaram a ganhar contornos de desumanidade extrema ao serem realizadas num cenário de pandemia. Além do Complexo do Alemão, apenas alguns dias depois, outros casos aconteceram em outras favelas da cidade e da região metropolitana. João Pedro Mattos Pinto, I 4 anos, foi assassinado no dia I8 de maio, no Salgueiro, no município de São Gonçalo, dentro de sua casa, durante operação das polícias civil e federal. Foi atingido por um tiro de 
fuzil e levado de helicóptero. Sua família ficou sem notícias sobre seu paradeiro por 24 horas até localizar seu corpo, já sem vida, no Instituto Médico Legal (IML). ${ }^{6}$ Sua casa, onde foi morto, tinha 72 marcas de tiro. ${ }^{7}$ Um dia depois, o jovem Iago Gonzaga foi torturado e morto pela polícia de acordo com relato de moradores de Acari. ${ }^{8}$ No dia 20, João Vitor Gomes da Rocha, I8 anos, foi baleado durante a entrega de doações realizada pela Frente da Cidade de Deus Contra a Covid-I9. ${ }^{9}$ O rapaz foi levado com vida para o hospital, mas não resistiu aos ferimentos e veio a óbito. Todas as mortes foram noticiadas pelas redes sociais de ativistas e grupos mobilizados nos locais, e noticiadas por meios de comunicação comercial.

O caso do assassinato de João Pedro durante operação das polícias civil e federal para cumprir dois mandados de prisão teve enorme repercussão, pois familiares e amigos utilizaram as redes sociais para tentar encontrar o rapaz quando ainda não sabiam seu paradeiro. Sua morte gerou mobilização também nas redes sociais através da hastag João Pedro Presente. ${ }^{10} \mathrm{O}$ nome do rapaz seguido da palavra "Presente" faz parte da gramática de movimentos de mãe e de favela que têm no não esquecimento das vítimas de violência estatal uma agenda fundamental.

Quando militantes se reuniram no dia 22 de maio na Cidade de Deus para gritar por seus mortos, não faziam isso pela primeira vez. Não era a primeira vez que se encontravam na dor e na solidariedade. As pessoas que estiveram juntas ali, que já estavam passando seus dias acionando parceiros externos para realização de doações, higienizando aquilo que era recebido, cadastrando famílias, percorrendo diferentes regiões das favelas onde vivem distribuindo cestas básicas e kits de higiene, pensando e realizando formas de comunicar para seus vizinhos o que acontecia e a necessidade do emprego das medidas de contenção de riscos... essas pessoas pararam. Reuniram-se para falar mais uma vez das mortes causadas por outra violência estatal, desta vez no período de pandemia. A violência marcada pela

\footnotetext{
${ }^{6}$ De acordo com dados do Instituto de Segurança Pública (ISP), isto é, dados de órgão ligado ao governo do estado, foram 177 mortes "em decorrência de intervenções de agentes públicos, $43 \%$ a mais do que no mesmo mês no ano passado e o equivalente a uma morte a cada quatro horas". A comparação tem como base dados referentes ao mês de abril e foram divulgados em reportagem de Júlia Barbon para o jornal Folha de S. Paulo, em 26 de maio de 2020. Ver em:

<https://www1.folha.uol.com.br/cotidiano/2020/05/mortes-por-policiais-crescem-43-no-rj-durante-quarentena-na-contramao-decrimes.shtml>.

${ }^{7}$ Ver em: <https://www.bbc.com/portuguese/geral-52731882>.

${ }^{8}$ Ver em: <https://g1.globo.com/rj/rio-de-janeiro/noticia/2020/05/19/moradores-da-favela-de-acari-afirmam-que-jovem-foitorturado-e-morto-durante-operacao-policial.ghtml>.

${ }^{9}$ Ver em: <https://www1.folha.uol.com.br/cotidiano/2020/05/intenso-tiroteio-interrompe-doacao-em-favela-no-rio-e-jovemmorre.shtml>.

${ }^{10}$ Ver em: <https://www.brasildefato.com.br/2020/05/27/em-memoria-de-joao-pedro-800-organizacoes-denunciam-violencia-doestado-nas-favelas>.
} 
crueldade, pelo racismo, pela falta de empatia, pela desumanização do outro. A nota pública escrita pelo grupo ali presente naquele dia denunciava as operações policiais, a militarização dos territórios e as violações dos corpos:

Viemos por meio desta nota, mesmo ao limite de nosso esgotamento e forças, dizer que esta estratégia de morte não deve ser mais tolerada por nenhum morador ou moradora de favela, e que a sociedade de forma geral que também habita espaços de privilégio deve se levantar contra o estado racista que nos viola cotidianamente. [...] Não toleraremos mais nenhuma morte. A política de segurança do estado do Rio de Janeiro é um risco à vida física e à saúde, física e mental, de milhares de moradores e moradoras de favelas e periferias. Witzel, a culpa é sua! ${ }^{11}$

O texto foi assinado pelo Movimento Favelas na Luta. Naquele momento, George Floyd ainda não havia sido assassinado nos Estados Unidos. Mas muitas pessoas já estavam gritando que não podiam respirar. Menos de dez dias depois, no dia 3I de maio, e no cenário de protestos e manifestações em diversas cidades estadunidenses, com ampla adesão, voltaram a se encontrar fora da internet e fora do contexto de doações.

George Floyd, homem negro, foi assassinado por sufocamento por um policial branco em Minneapolis (EUA), no dia 25 de maio de 2020. Enquanto era asfixiado, foi possível ouvilo dizer "não consigo respirar". O ocorrido foi filmado e divulgado nas redes sociais, gerando grande comoção, dentro e fora do país, manifestações e protestos intensos em diversas cidades e rearticulando denúncias e ações em torno da campanha sintetizada na hashtag Black Lives Matter (em português, \#VidasNegrasImportam).

A articulação internacional de militantes de coletivos, organizações e movimentos de favelas não era inédita. A pesquisadora Geísa Mattos iniciou, em 2015, um estudo sobre as conexões entre militantes brasileiros e estadunidenses do movimento Black Lives Matter (BLM). De acordo com a autora:

Este movimento teve seu auge entre 2014 e 20I6, com a promoção de protestos nas redes sociais digitais e nas ruas de cidades nos Estados Unidos, depois da divulgação de uma sequência de vídeos captados por câmeras de celulares ou de segurança, flagrando cenas de violência racista de policiais, a maioria homicidas.

\footnotetext{
${ }^{11}$ Texto compartilhado por pessoas e ações coletivas de favelas do Rio de Janeiro, em maio de 2020.
} 
Ainda em Nova York, participei de um encontro promovido pela ONG Witness, em que Raull (Santiago) e também Débora Silva, do Movimento Mães de Maio (SP), falaram a uma plateia de ativistas do BLM e de representantes de organizações internacionais de direitos humanos. Chamava a minha atenção a ênfase dos brasileiros em denunciar a violência policial enquanto violência racial. (MATTOS, 20I7, p. 74)

A análise da pesquisadora vai ao encontro do que minha pesquisa de doutorado(SOUZA, 2017), e outras pesquisas, como a de Livingstone (2017), também constatou: uma maior articulação entre debate e demandas das lutas dos movimentos de favela com as pautas raciais; a crescente conexão entre movimentos de favelas que tinham a comunicação como ferramenta central (caso do Coletivo Papo Reto, do qual Raull Santiago foi fundador e é integrante) e outros movimentos por direitos humanos, como os de mães de vítimas do Estado (do qual Débora Silva é uma das representantes mais conhecidas); e a circulação de ativistas de tais movimentos para fora do país, sobretudo Estados Unidos e alguns países da Europa, através da mediação de organizações internacionais com a pauta dos direitos humanos, como a Witness ${ }^{12}$ e a Anistia Internacional (com sede no Rio de Janeiro e que tem e já teve pessoas ligadas aos movimentos negro e de favelas em seu quadro de funcionários e colaboradores). Começou a haver uma percepção compartilhada ainda mais acentuada de que "a 'favela' é o lócus onde o racismo se efetiva, tendo por forma exemplar a abordagem policial discriminatória" (MATTOS, 20I7, p. 78).

Em sua tese de doutorado em Antropologia, Charlotte Livingstone (2017) acompanhou as ações do Coletivo Papo Reto no Complexo do Alemão, tendo, inclusive, sido incorporada ao grupo. A antropóloga mediou visitas de jornalistas estrangeiros ao lugar para conhecer e acompanhar uma parte do trabalho de ativismo realizado ali. Reconheci algumas das fotografias feitas por tais jornalistas em uma exposição internacional na cidade de Santiago, no Chile, em 20I7, o que comprova que a circulação de pessoas, imagens e informações sobre tais ações coletivas é muito mais ampla do que aparenta. Em sua pesquisa, Livingstone ainda relata as muitas atividades e mobilizações que acompanhou como ativista e antropóloga que tinham a pauta racial como núcleo. Foi o caso, por exemplo, da Marcha Contra o Genocídio da Juventude Negra, parte da iniciativa "REAJA!", que teve início no complexo de favelas de Manguinhos, também na zona norte da cidade do Rio de Janeiro, indo até o Morro do Alemão, dentro do Complexo do Alemão.

\footnotetext{
12 Disponível em: <https://portugues.witness.org/>. Acesso em: 12 abr. 2021.
} 
Livingstone e eu fizemos nossos trabalhos de campo no mesmo período e estivemos juntas na marcha, e também em outras atividades organizadas por ações coletivas diversas em que estiveram presentes pessoas ligadas a movimentos e coletivos do Complexo do Alemão. Nelas, era evidente a presença cada vez mais central do debate sobre raça e racismo. Desde o início dos anos 200o, quando comecei a acompanhar projetos sociais e movimentos de juventude e favela, essa pauta não havia sido colocada de maneira tão enfática, passando, como aponta Mattos (2017), a integrar a "racialização" de tais movimentos e grupos. Em suas palavras, “'A favela como quilombo de resistência' é uma das metáforas pelas quais a racialização tem sido expressa na linguagem dos ativistas cariocas contemporâneos" (p. 85).

Não é de se estranhar, portanto, que naquele mês de maio estabelecessem de maneira rápida a relação entre os assassinatos de jovens negros de favela que estavam ocorrendo no Brasil e o assassinato de George Floyd, nos Estados Unidos, que foi motivo de uma grande retomada do movimento Vidas Negras Importam em ambos países. O encontro Vidas Negras Importam, no Rio de Janeiro, foi convocado em caráter de urgência no último domingo de maio, e reuniu dezenas de pessoas, em sua maioria mulheres e homens negros, em frente ao Palácio Guanabara, sede do governo do estado do Rio de Janeiro, responsável pela política de segurança pública. Desta vez em maior número, com pessoas que apoiavam a causa, outros(as) ativistas, em conjuntura marcada pelas manifestações que aconteciam em diversas cidades dos Estados Unidos gritando mais uma vez: "Black lives matter", em inglês e em português, com ou sem hashtag. "Parem de nos matar!" "Nossos mortos não serão esquecidos!” "Nossas vidas importam!" “As vidas nas favelas importam!"

Manifestantes de máscaras no rosto buscavam manter espaço entre si. O tempo do ato foi limitado pelos(as) organizadores(as). Essas foram algumas das estratégias adotadas para que o protesto fosse realizado em meio à pandemia, gerando menos risco de contágio. Aos que criticaram a opção pelo encontro presencial, a resposta foi a seguinte: "Saímos para as ruas porque eles estão vindo nos matar dentro de casa. [...] O recado que deixamos ontem nas ruas é de que não sairemos nunca delas enquanto nossas vidas forem alvos dessa necropolítica racista e genocida", a qual consta como frases de abertura e de fechamento de documento escrito pelos(as) organizadores(as) após o ato e divulgado na página Favelas na Luta, no Instagram, e em perfis de participantes do movimento nas redes sociais, no dia I $^{\circ}$ de junho de 2020. 
A morte pela polícia se combinava, naquela conjuntura, à crescente constatação de que a pandemia também evidenciava desigualdades sociais e raciais, vitimando em maior número pessoas moradoras de áreas populares, como favelas e periferias. De acordo com Oliveira et al. (2020):

A pandemia da COVID-I9 no Brasil demonstra que regiões e populações são colocadas em condições de maior vulnerabilidade aos riscos de contaminação e morte. Partimos desses pressupostos para analisar o cenário nacional da pandemia da COVID-19. O país ocupa a 79- posição no ranking de desenvolvimento humano da Organização das Nações Unidas. Nos últimos anos, vê-se um aumento dos indicadores de desigualdade, atingindo sobretudo a população negra. Em 2018, no município do Rio de Janeiro, 30,5\% das pessoas negras (pretas e pardas) residiam em favelas, contra $14,3 \%$ de pessoas brancas. Em termos de cobertura de saneamento básico, negros são a maioria vivendo em locais com infraestrutura inadequada e exposição a vetores de doença: I2,5\% de negros residem em locais sem coleta de lixo e apenas $6 \%$ da população branca; sem abastecimento de água por rede geral, os negros representam $17,9 \%$, e brancos II,5\%; sem esgotamento sanitário por rede coletora ou pluvial, negros representam $42,8 \%$ da população contra $26,5 \%$ de brancos.

A desigualdade é evidente ao observarmos que 32,9\% dos negros compõem a parcela de brasileiros que vivem com até USD 5,50 por dia, além daqueles que vivem na linha da extrema pobreza, com rendimento de até USD I,90 por dia $(8,8 \%)$. O adensamento domiciliar excessivo dificulta o cumprimento das medidas de distanciamento intradomiciliar, recomendada para os casos positivos de COVID-I9. Em abril de 2020, foi publicado o Decreto no 10.329 que desobriga o fornecimento de serviços públicos e atividades essenciais, revogando, entre outros, a captação, o tratamento e a distribuição de água, e a captação e o tratamento de esgoto e lixo, agravando a situação de vulnerabilidade em locais já precarizados. (p.5)

Em texto sobre desigualdades raciais e a Covid-19, Oliveira et al. (2020) analisam múltiplas dimensões que devem ser consideradas ao refletirmos sobre tais desigualdades, incluindo a luta por dados oficiais que incorporem a raça, uma das faces do racismo estrutural que faz parte da realidade brasileira; mas também outras precarizações (como as do mercado de trabalho) que atingem preferencialmente a população negra e pobre. As múltiplas faces do racismo revelam-se ao se falar de favela e pandemia. Como foi visto até aqui (e como 
demonstram as autoras no trecho anterior), as condições de precariedade de políticas públicas nessas localidades fazem com que estejam mais vulneráveis a pandemias, como a da Covid-I9. Além disso, a violência policial, totalmente baseada em estereótipos raciais, tornase mais um complicador na hora de se mobilizar contra os efeitos do coronavírus. Tanto a violência, quanto a pandemia acabaram se apresentando como duas faces de uma mesma realidade: o genocídio da população negra, há décadas denunciado por movimentos negros e, mais recentemente, ressignificado e amplificado através de movimentos de jovens negras e negros e moradores(as) de favelas e periferias.

\section{"Nossos passos vêm de longe": reflexões finais}

Nem a pandemia da Covid-I9, nem a violência estatal foram resolvidas mais de um ano depois dos eventos e ações descritas e analisadas ao longo do artigo. No caso da pandemia, a demora na resposta de governos em variados níveis (com destaque para a falta de liderança e descaso das autoridades federais) nos leva a enfrentar, um ano depois, um período ainda mais alarmante. Já são mais de 390 mil pessoas mortas no Brasil, desigualmente distribuídas se consideramos critérios sociais e de raça que se traduzem, também, na distribuição espacial dos casos em cidades como o Rio de Janeiro. ${ }^{13}$

No que se refere à violência policial, membros de um conjunto de organizações sociais e de direitos humanos, incluindo algumas do Complexo do Alemão, redigiram documento pedindo o fim das operações policiais durante a pandemia. A repercussão de solicitações variadas chegou até o Supremo Tribunal Federal (STF) como Arguição de Descumprimento de Preceito Fundamental (ADPF) 635. ${ }^{14}$ Ainda que tenha sido acatado e resultado na diminuição momentânea do número de operações (e, portanto, de vítimas), foram em seguida retomadas,

\footnotetext{
13 "Na capital do Rio de Janeiro, os primeiros casos surgiram em bairros de classes média e alta, migrando para as áreas de favelas. Até 31 de maio de 2020, houve um total de 260 mortes nas grandes favelas, com destaque para Rocinha e Maré, com 55 e 48 , respectivamente ${ }^{44}$. Em São Conrado, bairro que faz limite com a Rocinha, foram contabilizados três óbitos até o dia 7 de maio de $2020^{45}$. Na Baixada Fluminense, um dos territórios mais pobres e violentos do estado, foi amplamente divulgada, na segunda quinzena de abril de 2020, a adoção do uso de contêineres para a permanência temporária de corpos, como em Duque de Caxias, devido ao aumento de óbitos e problemas de contágio nos cemitérios ${ }^{46}$. Esse município, no fim do mês de maio de 2020 , concentrou 1.502 casos, precedido por Nova Iguaçu, com 1.770" (OLIVEIRA et al., 2020, p. 6).

14 "O ministro Edson Fachin, do Supremo Tribunal Federal (STF), determinou a suspensão de operações policiais em comunidades do Rio de Janeiro durante a pandemia do novo coronavírus, salvo em casos absolutamente excepcionais, que devem ser devidamente justificadas por escrito pela autoridade competente e comunicadas ao Ministério Público estadual, órgão responsável pelo controle externo da atividade policial. De acordo com o ministro, nesses casos, deverão ser adotados cuidados para não colocar em risco ainda maior a população, a prestação de serviços públicos sanitários e o desempenho de atividades de ajuda humanitária. [...] A decisão foi tomada na Arguição de Descumprimento de Preceito Fundamental (ADPF) 635, em que o Partido Socialista Brasileiro (PSB) questiona a política de segurança pública do governador Wilson Witzel, que, segundo a legenda, estimula o conflito armado e 'expõe os moradores de áreas conflagradas a profundas violações de seus direitos fundamentais'." Disponível em: <http://www.stf.jus.br/portal/cms/verNoticiaDetalhe.asp?idConteudo=444960>.
} 
e diversas organizações voltaram ao STF denunciando o Governo do Estado e a Polícia Militar. Em abril de 202I, uma audiência pública foi convocada, na qual foram ouvidos representantes do estado, pesquisadores e movimentos e organizações sociais.

A frase que dá título a esta sessão tornou-se cada vez mais popular no interior de diversos movimentos sociais e entre ativistas. Ela se refere à construção da memória dos movimentos e de determinadas populações, sobretudo as racializadas e populares, que encontram nas histórias de seus ancestrais e antepassados inspiração para modalidades de resistência que são hoje construídas por estes em seus cotidianos. A ideia de ancestralidade, tão essencial para as religiões de matriz africana e para culturas e populações indígenas, é ampliada e ressignificada em contexto de resistência a políticas de cunho discriminatório e racista. São muitos não só os exemplos históricos do racismo das elites e do Estado, mas também são muitas as formas de organização para resistir a elas.

No caso das favelas e periferias em especial, tais estratégias e modos de organização passam, inclusive, pela resistência à remoção e a diferentes maneiras de expulsão dos territórios por elas e eles ocupados e transformados em casa, vizinhança, comunidade de afetos e sentidos. A comunicação popular e comunitária é criada como parte do repertório de lutas compartilhadas, nas quais tornar visível as violações de direitos entre tais populações, bem como expressar potencialidades e modos de organização é central para a transformação, ainda que lenta, nas formas como são vistas e tratadas pelo restante da sociedade e pelo Estado.

Aqui, buscou-se refletir sobre modalidades de organização e resistência que atualizam e transformam formas de comunicação comunitária que tradicionalmente fazem parte de seus repertórios de luta e atuação política. Estratégias reconhecidas historicamente, como o uso de faixas, carros e bicicletas de som ou distribuição de panfletos, são usadas simultaneamente a redes sociais e outras plataformas virtuais, como YouTube. Não há substituição, mas convivência entre modos mais ou menos atuais de comunicação e mobilização. E, para além dos meios de comunicação e estratégias empregados, existem arranjos organizativos que são recuperados e, a partir deles, aprendizados são passados entre diferentes gerações de pessoas que integram organizações e ações locais.

O cenário da pandemia global da Covid-I9 revela, por meio de eventos críticos ensejados pela própria pandemia em contexto de recorrente violência estatal, que ações coletivas locais, em articulação com outros atores sociais, criam e expandem redes de solidariedade e ajuda para que consigam denunciar e minimizar seus efeitos que são ainda mais agudos sobre populações historicamente tratadas pelo Estado como "margens" (DAS; POOLE, 2008). 
Tais coletivos, organizações e movimentos sociais, aqui representados por aqueles que têm a comunicação como uma de suas estratégias centrais, atuam através de gritos, rachaduras (na ordem instituída) e plantios (para o futuro) (WALSH, 2020) ${ }^{15}$ presentes nos cotidianos dessas populações e amplificados em "eventos críticos", como os que foram tratados aqui. Para Walsh (2020), em diálogo com Paulo Freire, Maldonado-Torres, entre outras e outros:

\begin{abstract}
Os gritos não são apenas reações e expressões de medo. São também mecanismos, estratégias e ações de luta, rebelião, resistência, desobediência, insurgência, ruptura e transgressão diante da condição imposta de silenciamento, diante das tentativas de silêncio e, também, diante dos mesmos acumulados silêncios - impostos e estratégicos. Os gritos reúnem silêncio e demanda - assumem novas vozes sequestradas, subjetividades negadas, corpos, natureza e territórios violados e despojados. Como bem explica Maldonado-Torres, o grito de terror da colonizada ou do colonizado não é simplesmente uma expressão de horror e terror, pode ser entendido, portanto, de forma mais crítica, como uma prática e intervenção (política, epistemológica, ontológica-existencial) que aponta para e encaminha uma atitude decolonial e a ideia e possibilidade de decolonização. (p. 153, tradução livre $)^{16}$
\end{abstract}

Conclui-se, assim, que as estratégias e ações dos diferentes meios de comunicação comunitária aqui tomados para análise, intensamente atuantes durante a pandemia do coronavírus, podem ser compreendidos como prática e intervenção que aponta e caminha para a possibilidade de de(s)colonização. Atuando nas "rachaduras" do Estado, e contribuindo para alargar as brechas por elas criadas, tais coletivos, organizações e movimentos seguem semeando e cultivando modos de resistência e solidariedade, presentes no cotidiano das favelas e periferias nas quais se inserem, e que se tornam mais visíveis para o restante da sociedade na medida em que fazem ouvir e amplificam seus gritos através de faixas, vídeos, imagens, panfletos, cartazes, campanhas, distribuição de alimentos e

\footnotetext{
${ }^{15}$ No original, em espanhol, "gritos, grietas y siembras”.

${ }^{16}$ No original, em espanhol: "Los gritos no son solo reacciones y expresiones de susto. Son también mecanismos, estrategias y acciones de lucha, re-beldía, resistencia, desobediencia, insurgencia, ruptura y transgresión ante la condición impuesta de silenciamiento, ante los intentos de silenciar y, también, ante los mismos silencios - impuestos y estratégicos acumulados. Los gritos reúnen silêncios y reclaman - se apoderan de nuevas voces secuestradas, subjetividades negadas, cuerpos, naturaleza y territorios violados y despojados. Como bien explica Maldonado-Torres, el grito del espanto del colonizado o colonizada no es simplemente una expresión de horror y terror, se puede ser entendido, así más críticamente, como una práctica e intervención (política, epistemológica, ontológica-existencial) que apunta y camina una actitud decolonial y la idea y posibilidad de decolonización".
} 
informações que podem ser vistos e ouvidos por outros setores da sociedade graças a redes de relações construídas e cultivadas por eles e tornadas visíveis em momentos específicos através da internet e de suas plataformas e redes sociais.

\section{Referências}

CUNHA, M. B. da. et al. Cenas históricas da participação popular na constituição de um campo de fronteira nas favelas do Rio de Janeiro. In: RODRIGUES, R. I. (Org.). Vida social e política nas favelas: pesquisas de campo no Complexo do Alemão. Rio de Janeiro: Ipea, 20I6. p. I542.

CUNHA, M. B. da. et al. O desastre no cotidiano da favela: reflexões a partir de três casos no Rio de Janeiro. OSocial em Questão, ano XVIII, n. 33, 2015, p. 95-I22.

CUSTODIO, L. da C. Favela media activism - Political trajectories of low-income Brazilian Youth. Dissertação (Mestrado) - Escola de Comunicação, Mídia e Teatro, Universidade de Tampere, Tampere, Finlândia, 2016.

DAS, V. Critical events - an anthropological perspective on contemporary India. Nova Deli, Índia: Oxford University Press India, 1999.

DAS, V.; POOLE, D. El estado y sus márgenes. Etnografías comparadas. Cuadernos de Antropología Social, UBA/Buenos Aires, n. 27, 2008.

INSTITUTO RAÍZES EM MOVIMENTO. Vamos desenrolar: produção de conhecimento e memórias. Caderno Devolutiva 20I3. Rio de Janeiro: TV Tagarela, Praça do Conhecimento, 2013.

LÂNES, P. Pandemia, violência e resistências nas favelas - vidas negras importam? Observatório Covid-19. CEMI - Centro de Estudos em Migrações Internacionais/Unicamp, 3 jun. 2020. Disponível em: <https://cemiunicamp.com.br/observatorio-no-62/>. Acesso em: 03 jun. 2020.

LEITE, M. P. Biopolítica da precariedade em tempos de pandemia. DILEMAS - Revista de Estudos de Conflito e Controle Social, Reflexões na Pandemia, texto 23, p. I-I6, 2020. Disponível em: $<$ https://www.reflexpandemia.org/texto-23 $>$. Acesso em: I4 maio 2O2I. LIVINGSTONE, C. Luto e luta (grief and struggle): favela activism, human rights and black genocide in Rio de Janeiro. PhD Thesis in Anthropology, Goldsmiths College, UK, 2017. 
MANO, A. D. Dispositivos de mobilidade: estética, precariedade e legibilidade no marco de dez anos da "favela modelo". 20I8. Dissertação (Mestrado em Ciências Sociais) - Programa de Pós-graduação em Ciências Sociais, Universidade do Estado do Rio de Janeiro, Rio de Janeiro, 2018.

MARTINS, G. Militarização da vida e censura da comunicação comunitária: a luta por liberdade de expressão no Conjunto de Favelas da Maré. 2018. Dissertação (Mestrado em Educação, Comunicação e Cultura em Periferias Urbanas) - Faculdade de Educação da Baixada Fluminense, Universidade do Estado do Rio de Janeiro, Rio de Janeiro, 2018.

MATTOS, G. A favor da favela: racialização no enfrentamento do estado e das elites. In: COMERFORD, J. et al. (Orgs.). Questões e dimensões da política. Rio de Janeiro: Papéis Selvagens, 2017. p.69-92.

MILLER, D.; SLATER, D. The internet: an etnographic approach. Oxford: Routledge, 2000.

OLIVEIRA, R. G. de. et al. Desigualdades raciais e a morte como horizonte: considerações sobre a COVID-I9 e o racismo estrutural. Cadernos de Saúde Pública, v. 36, n. 9, 2020.

RODRIGUES, R. I. Introdução e uma construção complexa: necessidades básicas, movimentos sociais, governo e mercado. In: RODRIGUES, R. I.(Org.). Vida social e politica nas favelas: pesquisas de campo no Complexo do Alemão. Rio de Janeiro: Ipea, 20I6. p. II-I4, 43-70.

SOUZA, P. L. A. de. Entre becos e ONGs: etnografia sobre engajamento militante, favela e juventude. 20I7. Tese (Doutorado em Antropologia) - Instituto de Ciências Humanas e Filosofia, Programa de Pós-graduação em Antropologia, Universidade Federal Fluminense, Niterói, 2017.

THAMARA, T. Quando o coronavírus chega à favela: "Apesar de estarmos no mesmo mar turbulento, não dividimos o mesmo barco". Revista Marie Claire, 28 mar. 202O. Disponível em: $<$ https://revistamarieclaire.globo.com/Comportamento/noticia/2020/o3/quando-ocoronavirus-chega-favela-apesar-de-estarmos-no-mesmo-mar-turbulento-naodividimos-o-mesmo-barco.html>. Acesso em: 03 abr. 2020.

TILLY, C. From mobilization to revolution. Nova York: McGraw-Hill, 1978.

VELLOSO, J. P. dos R. et al. Favela como oportunidade: plano de desenvolvimento de favelas para sua inclusão social e econômica (Complexo do Jacarezinho e do Alemão). Rio de Janeiro: Instituto Nacional de Altos Estudos, XXV Fórum Nacional, 2013.

WALSH, C. ¿Interculturalidad y (de)colonialidad? Gritos, grietas y siembras desde Abya Yala. In: LOSACCO, J. R. (Org.). Pensar distinto, pensar de(s)colonial. Caracas: Fundación Editorial El Perro y la Rana, 2020. p. I39-178. 